\title{
Prática psicológica em territórios sanitários: (re)vendo a ação clínica
}

\author{
Psychological practice in sanitary territories: (re)seeing the clinical action
}

\section{Jéssica de Almeida Félix e Ana Maria de Santana}

Resumo: Este estudo versa sobre a prática do psicólogo no Núcleo de Apoio a Saúde da Família (NASF). O objetivo foi de ampliar o horizonte compreensivo acerca da atuação de psicólogos em territórios sanitários do Agreste de Pernambuco, em saúde mental. A metodologia eleita veio da Pesquisa Qualitativa ao lume dos indicativos formais da Fenomenologia Hermenêutica. Os colaboradores do estudo foram profissionais psicólogos com atuação na saúde pública. Os recursos metodológicos para a obtenção dos dados foram: a Entrevista Narrativa e o Diário de Campo da pesquisadora. Na compreensão dos dados narrativos recorreu-se a hermenêutica gadameriana enquanto postura epistemológica de investigação. À guisa de consideração, a prática psicológica em territórios sanitários do Agreste de Pernambuco precisa transcender uma visão fragmentada da atenção prestada ao usuário, na maioria das vezes, exercida no modo de uma clínica desatenta a dimensões existenciais do enfermo. No matriciamento, empecilhos impedem o alcance de metas. Há exigência de atendimentos individualizados, devido à falta de esclarecimentos do saber-ofício do psicólogo na Atenção Básica. Seguindo o caminho das constelações acerca do cuidado em saúde, o estudo realça possibilidades compreensivas à luz da Fenomenologia Existencial.

Palavras-chave: Saúde pública; Matriciamento; Psicologia; Fenomenologia existencial.
Abstract: This study deals with the practice of the psychologist at the Family Health Support Center (NASF). The objective was to broaden the comprehensive horizon about the performance of psychologists in health territories of Agreste de Pernambuco, in mental health. The chosen methodology came from Qualitative Research to the light of the formal indications of Hermeneutic Phenomenology. The study collaborators were professional psychologists working in public health. The methodological resources for obtaining the data were: the Narrative Interview and Field Diary of the research. In understanding the narrative data, Gadamerian hermeneutics was used as an epistemological posture of investigation. By way of consideration, psychological practice in sanitary territories in Agreste de Pernambuco needs to transcend a fragmented view of the attention given to the user, most of the time, exercised in the manner of a clinic inattentive to the patient's existential dimensions. In matriculation, obstacles prevent the achievement of goals. There is a requirement for individualized care, due to the lack of clarification on the psychologist's know-how in Primary Care. Following the path of constellations about health care, the study highlights comprehensive possibilities in the light of Existential Phenomenology.

Keywords: Public health; Matriculation; Psychology; Existential phenomenology.

\footnotetext{
1 Mestra em Saúde Mental (Universidade de Pernambuco/UPE); Sanitarista (Escola de Governo em Saúde Pública de Pernambuco (ESPPE); Psicóloga (UPE). E-mail: jessicaalmeida.jec@gmail.com .

2 Doutora em Psicologia Clínica; Mestra e Especialista em Psicologia Clínica (UNICAP). Psicóloga (UFPE). Professora Adjunta do Curso de Psicologia da UPE atuando na Graduação e no Stricto Sensu. Pesquisadora do Laboratório de Pesquisa em Ação Clínica e Saúde - LACS/UPE. Membro do GT- Práticas Psicológicas em Instituições: atenção, desconstrução, invenção da ANPEPP. Psicóloga da Secretaria de Saúde do Recife. E-mail: ana.santana@upe.br .
} 


\section{Introdução}

O Núcleo de Apoio a Saúde da Família (NASF) foi criado com o objetivo de fortalecer as ações de saúde na comunidade. Nesse intento, procura realizar procedimentos que auxiliam a efetivação da Atenção Básica voltada para 0 comunitário e sua família. Inserido no NASF, o psicólogo encontra numerosos desafios, entre eles, a falta de esclarecimento sobre o saber-ofício em saúde mental junto à comunitários. Sendo assim, importa saber - como a prática psicológica vem sendo realizada no NASF? Quais os desafios junto às demandas comunitárias relacionadas ao sofrimento em cidadania? Na experiência clínica das pesquisadoras, tais questões levam a deduzir que no campo da formação clínica e nas práticas de atenção em saúde, o psicólogo não se encontra tão bem esclarecido para atuações que ultrapassam a sua fronteira disciplinar, 0 que motiva a busca de investigação sobre a práxis psicológica em territórios sanitários.

0 NASF não é porta de entrada para a Atenção Básica, avistada como mais um apoio especializado às equipes de Estratégia Saúde da Família (ESF). A Atenção Básica diz de um conjunto de ações que podem ser realizadas individualmente ou coletiva, nos primeiros níveis de atenção do sistema de saúde, voltada para a prevenção de agravos, tratamento e reabilitação (PNAB). No fazer das práticas multiprofissionais do NASF, encontra-se a assessoria das equipes do ESF, buscando ampliar ações e articulando a rede de saúde no território sanitário. 0 trabalho é processual, criado com atores sociais envolvidos na promoção do cuidado, são eles: equipe técnica do ESF, comunitários e organizações sociais da comunidade. As ações no NASF, dizem de um atendimento compartilhado em domicílio, junto a comunidades, individualmente ou em intervenções clínicas grupais e de educação em saúde. 0 apoio matricial em clínica ampliada e o Projeto Terapêutico Singular são dispositivos importantes que dão lume ao trabalho dos que formam o NASF, executando diretrizes das políticas do Ministério da Saúde.

Um grande obstáculo no exercício profissional dos integrantes do NASF são os modos de atuação embasados nos princípios da biomedicina, vigente e hegemônica, em que a lógica da atenção diz de uma clínica que naturaliza, indiscriminadamente, demandas de cunho sócio-político. Parafraseando Pelizzoli (2011) 0 termo biomedicina assinala o naturalismo vigente nas práticas de saúde, em especial, diante do sofrimento no campo sanitário. Importante real çar que a população assistida, assim como os técnicos dos serviços, esperam do psicólogo que atenda individualmente nos modos de uma clínica consultorial, como estratégia de atenção ao sofrimento de comunitários, tal como é realizado nos ambulatórios de saúde. № âmbito das intervenções do NASF, as demandas requerem procedimentos transdisciplinares na modalidade grupal ou individual (Brasil, 2009).

Perrella (2015) comunica que nas atuações do NASF encontram-se dificuldades em trabalhar de maneira articulada com as equipes, percebe a predominância de práticas que pouco contribuem para a promoção do cuidado com os usuários e familiares em ações cotidianas de saúde. Klein e D'Oliveira (2017) afirmam sobre dilemas entre o que é exigido nas tarefas e o que é possível de ser realizado no cotidiano em relação a organização e divisão de tarefas para o matriciamento. Concomitante, Leite, Andrade e Bosi (2013) destacam a grande ocorrência de demandas em saúde mental, sendo assim, é preciso rever a atuação do agente de saúde mental nesse âmbito, dentre eles, o psicólogo no campo do NASF, vez que encontram-se desafios em trabalhar a interdisciplinaridade na Atenção Básica. A formação em Psicologia para a atuação intersetorial e interdisciplinar nesse campo, não vem acompanhando as práticas que procuram, cada vez mais, novos modos de responder às demandas de saúde nos territórios.

Ferreira Neto (2010) diz que as ações dos psicólogos no NASF revelam a tendência de reproduzir o modelo centrado no atendimento individual, sem valorizar a criação e a dinâmica necessárias no campo da saúde. Compreende que predomina a lógica do atendimento clínico de natureza consultorial. Nessa esteira compreensiva, na prática psicológica são vistas dificuldades significativas em relação a sua integração com os demais saberes e práticas na elaboração do projeto terapêutico singular do cliente assistido, no exerćício de uma clínica ampliada relevante em contextos de saúde. A ação nessa área tem particularidades, uma delas é de uma abordagem clínica construída pelos atores envolvidos, incluindo profissionais, organizações sociais e comunitários. Nesse sentido, é necessário refletir criticamente, as políticas que vem servindo de norte às atuações indo além de procedimentos e métodos de um saber-fazer nesse campo.

Nos últimos anos, nas instituições sanitárias ou em comunidades, a atuação do psicólogo em saúde tem se mostrado através de várias modalidades. Estudos recentes estão pondo em reflexão a ação clínica neste fazer, afirmam sobre um modo de ouvir com solicitude aquele que busca atenção comunicando um sofrimento (Braga, Mosqueira e Morato, 2012). Acompanhando as autoras, as intervenções em instituição precisariam ver a inserção e a interação dos sujeitos em seus grupos, o que pode sinalizar dimensões existenciais na lida diária de ser-no-mundo-com outros. Entendemos que atuar neste campo, requer um olhar à práxis, podendo transcender ao solicitado pela gestão dos serviços e da formação profissional, vez que ainda elegem uma clínica de natureza consultorial no âmbito sanitário. Sobre este fato, Ferreira Neto, informa:

A progressiva e permanente transformação do SUS e a prática requerida aos psicólogos nesse setor permitiram significativos avanços no desenvolvimento de uma atuação mais pertinente e resolutiva por parte dos psicólogos; entretanto, como mostra parte da literatura recente, ainda há muito a ser revisto. Temos um cenário que aponta a importância da ampliação das ações no trabalho dos psicólogos na saúde mental, ampliando não somente a clínica, mas também as intervenções extraclínicas (2010, p. 401).

Caldas e Macedo (2011) salientam que o psicólogo antes de intervir precisaria conhecer o cotidiano dos coletivos nos espaços da comunidade, compartilhando com os usuários do serviço possibilidades de atendimento, sendo estes protagonistas na atenção. Em contrapartida, a instituição poderá acolher 0 fazer deste profissional, rompendo com as práticas hegemônicas do cuidado em saúde, saindo do modelo biomédico pautado na patologia e categorizações, adentrando em dimensões políticas, culturais e sociais das demandas que assinalam sofrimento. Por essa compreensão, o lume dos pressupostos fenomenológicos existenciais do pensamento heideggeriano podem servir como possibilidade para ampliar horizontes compreensivos da prática psicológica no NASF, dessa vez, realçando a experiência clínica como espelho axial que permite refletir diversas faces do fazer psicológico junto às demandas que a ele recorrem.

Este estudo ao eleger como objeto de investigação a práxis psicológica no NASF procura contribuir para esclarecer sobre a ação do psicólogo nesse contexto. A procura pelo atendimento psicológico, seja espontânea, ou por encaminhamentos, vem crescendo gradativamente, muitas são as queixas trazidas, daí ser significativo compreender a prática do psicólogo no NASF, 0 que leva a problematizar o imaginário da população e dos técnicos da saúde sobre a prática psicológica. Esta pesquisa elege a Fenomenologia Herme- 
nêutica Existencial como via à compreensão do que se mostra no âmbito da prática psicológica no NASF. Nesse propósito, recorre aos indicativos formais heideggerianos acerca da existência humana que contribuem para pensar a racionalidade moderna no campo da saúde, em especial, na intervenção de psicólogos.

0 fazer do psicólogo na saúde pública é permeado por demandas complexas de atores sociais em situação de crise, daí ser preciso ir além dos modelos de atenção configurados, tradicionais deste campo. Dessa feita, 0 objetivo deste artigo é o de ampliar possibilidades compreensivas acerca da prática psicológica no Núcleo de Apoio a Saúde da Família (NASF), situado no Agreste de Pernambuco.

\section{Método: experiência clínica como meio de investigação da prática psicológica em saúde.}

Lançar o olhar sobre a experiência de psicólogos no NASF implica compreender a ação clínica a partir de suas atuações. Desse modo, importa revisitar noções acerca da experiência humana, como diz Benjamin (1994), ela é a matéria prima das narrativas. 0 narrador é levado a novas traduções de sua vivência, entrançada na experiência coletiva da qual está inserido.

0 caminho metodológico para compreender a prática de psicólogos foi a Entrevista Narrativa citada em Flick (2009) e o Diário de Bordo de Aun (2005), trazendo à luz as experiências clínicas vividas por psicólogos em territórios sanitários. 0 cenário da investigação foi o Núcleo de Apoio a Saúde da Família - NASF do Município de Venturosa, Agreste de Pernambuco. A metodologia eleita se insere nas abordagens qualitativas de pesquisa tendo como lume os pressupostos da fenomenologia heideggeriana. Trata-se de uma investigação que procurou compreender a experiência clínica de psicólogos como horizonte a ser alcançado (Santana, 2017). 0 estudo fenomenológico tem como pressuposto a ideia de homem e mundo numa co-pertinência originária. Logo, o pesquisador é o próprio instrumento metodológico da pesquisa, quando comunica a sua compreensão. Os sujeitos colaboradores foram psicólogos que trabalham no contexto do Núcleo de Apoio a Saúde da Família (NASF) ou já atuaram no campo da saúde pública. A Entrevista Narrativa viabilizou o sentido atribuído pelo entrevistado a sua prática clínica. Um procedimento de produção de dados, considerado como método de pesquisa qualitativa não estruturado (Flick, 2009).

Compreendendo método como caminho a ser trilhado na busca do que se investiga, este estudo recorreu ao Diário de Bordo como instrumento que favorece a comunicação da experiência de psicólogos clínicos no NASF. Trata-se de um registro em que nele se encontram as rememorações do vivido e do que foi sentido nas situações convividas (Aun, 2005). Encontra-se no Diário de Bordo o dizer, revelando marcas da experiência, compartilhadas pela escrita, possibilidade de elaboração de sentidos em narrativa. Os diários dizem das afetações na clínica, da abertura frente ao que se mostra, da atitude frente ao inesperado (Prado e Caldas, 2015). Como lembra Braga et al. "A cartografia clínica parte da escuta psicológica visando tanto à investigação, quanto à intervenção: busca compreender o cenário social, criar modos de atuação possíveis e pesquisar a própria intervenção em ação" (2012, p.560).

A Análise das narrativas recorreu a Hermenêutica Filosófica de Gadamer, no que realça sobre a Fusão de Horizontes, enquanto possibilidade que designa a experiência de mundo. Gadamer (1999) sinaliza o sentido de compreensão enquanto hermenêutica em Heidegger, diz da dimensão ontológica do homem enquanto existencial que lhe constitui, ou seja, ser-homem é ser-compreensão, como realça Heidegger (2012). Nesse sentido, compreensão não é da ordem de um comportamento subjetivo frente a um objeto dado, mas pertence à abertura existencial ao ser daquilo que é compreendido. Portanto, a hermenêutica não visa impor uma forma de pensar ou de pesquisar, antes determinada por modelos de investigação, hermenêutica em Gadamer revela horizontes compreensivos, a partir de um diálogo entre interlocutores.

Inspirado na Perspectiva Fenomenológica Existencial, este estudo sinaliza a seguir o desfecho dos encontros com os colaboradores. As narrativas permitiram ver dificuldades e sugestões que auxiliam, de certo, a reinvenção do saber-fazer em territórios sanitários, luz para um novo modo de olhar a prática psicológica. É relevante noticiar que essa pesquisa foi aprovada no Comitê de Ética da Universidade de Pernambuco - UPE sob o número do CAAE 85826618.7.0000.5207 e parecer 2.577.184. Passamos, agora, a dialogar com as contribuições dadas ao estudo, uma discussão necessária.

\section{Discussão: entre(vistas) acerca da fenomenologia da ação clínica de psicólogos em territórios sanitários}

As entrevistas narrativas com as psicólogas Sakura e Hinata, nomes fictícios, lançaram luzà compreensão sobre a prática psicológica no território sanitário. Dimensões significativas foram também reveladas no Diário de Bordo da pesquisadora, quando realizava a pesquisa no cotidiano das tarefas do Núcleo de Apoio a Saúde da Família.

\section{Sakura: Primeiras impressões}

Sakura: A minha experiência no SUS é desafiadora, primeiro porque a gente sai de uma lógica de pensar clínica[...] a clínica"fechada", de consultório ambulatorial, de elite [...] a tradicional clínica psicológica. No meu caso, foi um desafio pensar[...] [a clínica] fora das quatro paredes. Saber que é preciso [para todos][...] não é somente para as pessoas que tem uma condição de pagar[...] Cuidar da saúde em termos de uma prática psicológica, de uma psicoterapia, é caro[...] muito caro.

Sakura sinaliza as dificuldades em conceber uma psicologia que possa transcender modelos tradicionalmente instituídos. Em sua narrativa, é perceptível que além das resistências profissionais para superar obstáculos, ocorre a falta de conhecimento sobre o fazer do psicólogo em comunidade pela população e por colegas de trabalho. Sair do modelo da clínica tradicional é um desafio para todos os envolvidos, já sinalizado no Diário de Bordo da pesquisadora:

Pesquisadora - Hoje, houve incerteza no que devíamos fazer. Crescente demanda para atendimento individual, mesmo com a possibilidade de haver grupos. Dificuldades em inserir os sujeitos, empecilhos para a marcação com outros profissionais psicólogos[...] Sair do pensar de um fazer tradicional tem sido difícil. Percebo como é gigante atuar neste ambiente e as diversas possibilidades de ação e de contextos que o psicólogo está inserido, como em um tear de compreensões sigo estudando para entender qual meu "papel" neste ambiente.

Édesafiante pensar numa clínica que se mostra na desinstitucionalização de práticas e saberes. Franco Rotelli (1991) questiona os modos como acon- 
tecem o desinstitucionalizar no cotidiano das práticas. Reflete os mecanismos que possam reinventar os serviços de saúde, ou seja, as instituições que sugerem novas práticas devem estar à altura dos novos objetos de cuidado em saúde mental, auxiliando a pensar os manicômios, para que a mudança não seja somente de lugares. 0 autor informa que devemos ter atenção para não reduzir desinstitucionalização a saída do hospital psiquiátrico, nas palavras dele:"Devemos trabalhar no sentido desinstitucionalizar as relações familiares, os âmbitos sociais, os lugares de trabalho, os serviços sanitários, os serviços sociais e as instituições de controle social" (Rotelli, 1991, p. 04). Outro ponto realçado por Rotelli são as relações de poder e a transformação ocorrida pela desinstitucionalização, é preciso refletir e pôr em diálogo os modos como elas ocorrem. A ESF por envolver a população numa atenção que produz novos modos de cuidado é um norte às vias de transformação das realidades na saúde (1991). Nessa esteira, Sakura realça:

Então[...] já entrando na questão do NASF[...] o NASF entra com apoio matricial específico[...] 0 psicólogo entra com o olhar na questão da saúde mental daquelas pessoas, a gente não só escuta o contexto conturbado, o contexto difícil[...] a gente presencia[...] a gente vê[...] Muitas vezes você chega numa situação [diz] [...] "poxa isso poderia ser eu", também tem essa questão[...] sou profissional do SuS e também sou usuária[...] então[...] me vejo em muitas situações dessas. Assim[...] é um constante provocar-se, a gente se sente na situação. Empatia ocorre mesmo, naturalmente.

Sakura comenta sobre a afetividade vivida que lhe afeta, de uma clínica cartográfica que remete a quem se permite afetar, elaborando sentidos ao vivido, pondo em reflexão o instituído que a determina nas prática, abrindo-se aos fenômenos que surgem nas relações, como diz Rolnick (1989). Escutar 0 que advém da palavra que comunica o vivido do mundo é difícil, no entanto, é possivel enunciá-la a partir da experiência com o usuário.

Este diálogo remete ao que Rogers diz sobre empatia - palavra usada por ele para indicar uma relação que acolhe e compreende o outro, sendo sensível ao que the afeta na experiência do mundo, como diz: " [...]quando 0 terapeuta é sensível aos sentimentos e às significações pessoais que o cliente vivencia a cada momento, quando pode apreendê-los'de dentro' tal como 0 paciente os vê [...]" (1985, p. 72).

Após as considerações iniciais sobre o fazer psicológico, Sakura informa a compreensão elaborada de matriciamento em sua prática clínica no NASF:

Sakura: É desafiador você ir[...] no caso do NASF, tentar matriciar a equipe do Estratégia de Saúde da Família. Os profissionais não sabem que 0 psicólogo pode atuar fora do consultório[...] Quando eu chegava para fazer matriciamento[...] para fazer estudo de caso, eles me cobravam atendimento ambulatorial [e dizia] [... . "você vai ficar aqui e não vai atender não?".

Entendemos que ela realça o que já encontramos em nossa prática - matriciamento recorrendo a uma visão prévia que antecede a práxis. 0 matriciamento parece passar pela previsibilidade de uma lente que determina o saber-fazer. Sakura aponta para o desconhecimento do saber-fazer do psicólogo no âmbito da saúde pública. Em relação a isso, Medeiros faz uma crítica sobre o modo como está acontecendo o matriciamento. As equipes, além de não compartilharem o trabalho, a operacionalização dos encontros para tal fim, não ocorre - "Nem mesmo que o entendimento acerca da prática de matriciamento como lógica de articulação da rede seja unívoco ou conduza ao sucesso da estratégia de gestão em rede" (2015, p. 1168). Fato evidenciado na comunicação de Sakura que diz:
A prática do psicólogo no matriciamento em saúde mental, não é difundida. 0 psicólogo é tido como aquele profissional que faz psicoterapia[...] assim[...] é como se a gente não tivesse nada mais a contribuir[...] $\mathrm{Na}$ verdade, isso é uma ignorância das pessoas que não entendem[...] porque 0 NASF também é recente, né!!...] o NASF é de 2008 e a psicologia no Brasil é recente né[...] ela [psicologia] é uma profissão recente[...]. cinquenta e poucos anos[...], enquanto que outros profissionais aí.[...] medicina, enfermagem[...] são profissões milenares[...] sei lá[...] de muito e muito tempo.

Com isso, Sakura mostra que a formação acadêmica não contempla a prática de matriciamento do psicólogo no SUS, nem a população conhece. Nesse sentido, Galindo e Francisco (2013) contribuem quando pontuam esforços para analisar a psicologia de forma que responda a questões da saúde ligadas ao fortalecimento do SUS, ultrapassando as limitações, considerando o social, superando a ideia do individual e aproximando as questões políticas, já que o SUS é constituído a partir de mobilizações políticas. Sobre isso, ela expõe a necessidade de conhecer as Políticas Públicas, não para fixá-las enquanto determinantes de ações, mas para vislumbrar compreensões na atuação clínica. Além disso, aponta al go no cotidiano dos serviços de saúde - a ligação entre as questões emocionais e a medicalização compulsiva. 0 NASF como apoio poderia dar suporte às instituições, orientar e contribuir com 0 cuidado, porém vem enfrentando dificuldades.

Sakura: Porque a gente fica muito ligado[...] os profissionais como um todo[...] e as políticas na verdade de saúde[...] a gente ainda não saiu das Políticas Assistencialistas: estou com uma dor tomo remédio, estou com insônia[...]ansiolítico, estou triste um antidepressivo. Mas não tem aquele olhar do que está causando a insônia[...] o que vem sentindo ultimamente. Um olhar mais de causa ao invés de só olhar a sintomatologia do paciente. Eu via muito isso e a gente vê também um alto índice de automedicação e muitos clínicos (médicos) passando ansiolíticos[...] receitando[...] quando se sabe que tem que ser um profissional neurologista ou psiquiatra[...]mas a gente sabe das dificuldades e não dá para ter todos esses profissionais. São profissionais caros para os municípios[...] na verdade os municípios teriam condição suficiente[...] mas a gente vê questões políticas no SUS.

Sakura: Por ser um Sistema de Gestão Pública tem a questão das complicações e todos os desvios[...] a política influencia muito na questão saúde e não tem como tirar a política[...] Porque a política é do humano[...] eu estou aqui falando com você, estou fazendo política! A gente tá em uma troca, então[...] é complicado, mas quando a gente vê que faz uma coisa, nem que seja uma coisa pequena[...] é como se tudo se renovasse. Valesse à pena 0 esforço. É trabalho de formiguinha, mas compensa e vale à pena.

Acima, Sakura contribui ao estudo quando refere um dos grandes desafios da atuação profissional, aponta a resistência das equipes em acolher as intervenções dos profissionais que trabalham nessa área e 0 pouco conhecimento sobre as diversas nuances da prática psicológica nas instituições de saúde. Destaca em sua narrativa: "A prática do psicólogo, na questão do matriciamento em saúde mental não é difundida, o psicólogo é tido como aquele profissional que faz psicoterapia [...] é como se a gente não tivesse nada mais a contribuir". O NASF é um dispositivo novo que ainda gera dúvidas com relação às suas funções, vale salientar que as lentes das Políticas Públicas, apesar de relevantes, assim como outras advindas da formação profissional, não dão conta do que vem se mostrando como demanda à atenção ao sofrimento comunicado nas práticas. É necessário reinventar. 
Entendemos que o matriciamento contribui para o cuidado no contexto da saúde, abrindo possibilidades para a escuta do que chega como queixa ou demanda, intervindo junto com a ESF nos casos solicitados, sem que com isso exerça o que não Ihe cabe, a exemplo, fazer psicoterapia individual ou de grupo. Sakura: "[...] o importante do NASF é justamente esse olhar "diferenciado". 0 psicólogo com seu olhar diferenciado sobre o processo saúde e doença [...] e sobre a possibilidade de intervenção".

A narrativa de Sakura informa que as afetações provocadas pela atuação psicológica no contexto comunitário, favorecem a todos. Quando atuamos, afetamos e somos afetados, essa é a nossa condição existencial de pertencer ao mundo, desse modo, somos originariamente abertura para o diálogo com-outro que se mostra acessível na experiência clínica. Nesse sentido, 0 fazer psicológico vem sendo compreendido no dizer de Sakura:

Sakura: E falando mais da prática psicológica, é um constante afetar-se[...] eu sou muito afetada, os contextos que eu vejo [...] às vezes eu saio com a sensação que eu fui mais ajudada que "ajudei" [...] eu com aquela postura de suposto saber[...] chego lá no contexto e vejo uma família totalmente desestruturada e "nossa essa poderia ser a minha"e em muitos casos é. E no final recebo um "obrigado", aí isso me mata. Obrigada? Como obrigada? Meu Deus do céu!. Assim é desafiador e no mais é recompensador[...] no meu caso, eu saio daquele lugar de suposto saber, compartilho a minha experiência que eu acho mínima, (amparo do encontro humano que na fusão de horizontes conduz a novas interpretações do vivido como ser-no-mundo) eu acho tão pequeno para o que eu recebo[...] mas vejo que surte efeito também em mim[...] porque quando eu saio dali não sou mais a mesma pessoa. É você poder transformar um pouco, sair dessa clínica elitizada, né?.

Ela refere a algo que faz parte do cotidiano dos profissionais de saúde, 0 lugar atribuído a eles - o suposto saber. Seríamos capazes de ter respostas ou soluções para as demandas de usuários? 0 trabalho do psicólogo não possui compromisso com demandas das pessoas, porém é uma realidade que se mostra constante nos serviços de saúde. Poder sair desse emaranhado de construções do imaginário social, refletindo sobre a atuação clínica psicológica, contribui para estarmos atentas para pensar o modo como nós psicólogos estamos indo ao campo da saúde.

Outra questão colocada no estudo é a chamada "clínica elitizada". Ir ao psicólogo, para muitos ainda é difícil. Um dos obstáculos seria a condição financeira que impossibilita o pagamento do serviço psicológico. Contudo, avista-se mudança com a implantação de práticas psicológicas em territórios, inseridas na saúde pública. Na opinião de Sakura, é possível "' [...]promover cuidados em saúde mental, mesmo que mínimo para as pessoas que necessitam". Nesse sentido, refere à relevância do psicólogo trabalhar em equipes, fazendo o diferencial ao trazer ações pelo olhar que viabiliza dimensões existenciais nas questões de saúde mental em campos públicos.

Sakura: Mas eu acho super importante o NASF e o profissional de psicologia no NASF, na equipe NASF faz toda a diferença! Porque eu passei quando fiz Residência por equipes que tinham psicólogos e equipes que não tinham, não querendo dizer que o serviço só funciona com ele[...] mas 0 psicólogo traz um olhar mais sensível às questões de saúde mental.

Pesquisadora: No seu olhar existe "o papel do psicólogo no NASF" isso épossivel?

Sakura: Sim teria um papel. 0 psicólogo no NASF traz um olhar diferenciado para as questões de saúde mental e ele também troca com o outro à medida que coloco o meu olhar e escuto o outro, amplio a minha possibilidade de atuação. Para também não ficar só fechada, só na questão "a é uma família problemática" estar em troca [de saberes] com o nutricionista, na questão do atendimento multiprofissional[...] do olhar também. 0 papel do psicólogo é justamente chamar a atenção para as questões emocionais[...] as questões de saúde mental [...] mesmo 'daquela família', quase sempre deixam passar, porque "a não, vamos olhar para a dor "'"vamos olhar ali para[...] ]está com um corte [exemplo] [...] aí a gente chama, mas porque ela se corta tanto?[...] porque ela só aparece com esses arranhões?[...] éassim eu não falo [somente] de coisas tão olho no olho como a pessoas que se corta[...]

\section{Pesquisadora: O que poderia ser feito para ampliar a prática psicológica} no NASF?

Sakura: [...]primeiro tem que vencer as barreiras políticas e por incrível que pareça às barreiras profissionais.

Sakura realça o Projeto Terapêutico Singular como área privilegiada de atuação em psicologia, vez que é pouco elaborado na realidade dos serviços. Algumas equipes preferem seguir procedimentos ambulatoriais como modo de resposta ao que é cobrado institucionalmente, dificultando a realização do matriciamento.

Sakura: 0 PTS às vezes é até extinto[...] As pessoas falam muito no PTS mais só na teoria[...] quando a gente vai ver o PTS do paciente se resume a entregar medicamento[...] aos hipertensos e diabéticos[...] olhe quando fazem o PTS do hipertenso e diabéticos né! Isso é indicador de monitoramento, indicador de dinheiro para o município. As linhas de cuidado, as políticas de saúde que dentro delas atravessam a linha de cuidado[...] já é do SUS é 0 modelo do SUS[...] regionalizado que procura concentrar os equipamentos fora dos grandes centros urbanos da capital e faz o percurso que o usuário iria percorrer para ter a sua saúde atendida integralmente efetivando 0 cuidado' $[. .$.$] .$

Nesse caminho,

Sakura: Eu acho que um dos maiores entraves para prática psicológica, não só para a prática psicológica, mas para a prática do NASF enquanto unidade matriciadora é a questão política[...] porque o que dá visibilidade política é 0 atendimento ambulatorial, é você atender pessoas e deixar as pessoas felizes no caso do psicólogo[...]parece até brincadeira, mas é verdade!

Revendo a psicologia em contextos de saúde, Sakura contribui quando sinaliza a falta de conhecimento acerca da atuação clínica psicológica "pelo desconhecimento, porque sofrimento não se tira de ninguém, o sofrimento é do humano, mas como colocar na cabeça principalmente dos profissionais, que querem que a gente atenda as pessoas e ela saia sorrindo".

As demandas da ESF, os procedimentos realizados a partir de uma clínica assistencialista e pouca difusão do trabalho no âmbito da promoção em saúde são fatores que interferem no modo como são realizados os encaminhamentos para as intervenções. Nas palavras de Sakura:"A Estratégia de Saúde da Família tem que dar conta de 80\% dos problemas de saúde e talvez por desconhecimento disso e pela supremacia da clínica assistencialista, por que o modelo de saúde ainda é um modelo assistencialista[...]. a promoção e a prevenção da saúde são pouco difundidas". Nesse sentido, urge a necessidade de novos horizontes em práticas voltadas às demandas comunitárias em saúde.

Importa ainda rever o que Sakura assinala sobre o consumo desenfreado de medicalização psiquiátrica, os ansiolíticos e antidepressivos funcionando 
como pílula mágica, passados sem a devida avaliação, fato que poderia ser evitado com as orientações no matriciamento em saúde.

Sakura:[...]até mesmo uma pessoa que faz uso de medicação, poderia ter evitado esse uso[...] até mesmo pelo desconhecimento. Um luto[...] a pessoa tá chorando por um luto, quando eu falo de luto não é só o de pessoas que morreram[...] está em uma fase fechando um ciclo da vida isso são pequenos lutos que a gente vivencia e sofre por isso[...] é preciso 0 sofrimento nessa situação também para elaborar um sentido novo para a vida dela e por desconhecimento do profissional às vezes ele encaminha para um psiquiatra e se o psiquiatra não tiver esse olhar ampliado[...] tem psiquiatras que tem esse olhar ampliado, mas tem psiquiatras que não, que vai prescrever logo um antidepressivo ou um ansiolítico e depois de três meses a pessoa está dependente "por que eu vou largar essa pílula do prazer, essa pílula que me deixa feliz?".

Ela Sinaliza a importância da medicação quando avaliada e prescrita adequadamente. As pessoas tornam-se viciadas encobrindo o que se revela na existência em sofrimento. A realização do apoio matricial as Equipe de Saúde da Família para a boa condução dos casos, mais uma vez é vista.

Sakura: Aí, nesse caso em específico, não estou falando dos casos que realmente necessita, porque tem aqueles casos que realmente necessitam, mas nesse caso específico[...] a pessoa vai sair de um condicionamento, de uma situação de sofrimento e vai se atrelar ao medicamento que é uma dupla dependência, ao mesmo tempo que fugia dos sintomas[...] da tristeza, insônia[...] da crise que estava vivendo vai se refugiar no medicamento, mas 0 que está em baixo na base que está causando[...]vai continuar ali encoberto e provocando, né.

0 olhar sobre a experiência de Sakura em nosso diálogo, mostrou a importância da ação psicológica no âmbito transdisciplinar, revelando o NASF como espaço significativo, requerendo do profissional uma visão ampliada que transcenda aos modelos de atendimento, previamente instituídos, trabalhando com a educação em saúde e se reinventando como profissional.

\section{Hinata - Sobre a teoria e a prática do território}

Iniciamos, agora, o diálogo com Hinata, que começa narrando sobre as incertezas vividas na formação profissional relacionadas às expectativas para o trabalho:

Quando saí da faculdade e entrei em um universo que não é tão teórico, a gente se depara com uma prática que de alguma forma diverge da teoria[...] tão estudada e tão agraciada e esperada, na verdade é um pouco triste, querendo ou não frustrante no primeiro momento pra gente. A gente espera de alguma forma fazer um trabalho que realmente venha a trazer melhorias para o sujeito e não consegue porque a realidade não permite[...] os meios não permitem!

Além das dificuldades nas tarefas clínicas, no imaginário das pessoas encontra-se a concepção de que o psicólogo somente atua em clínica individual na modalidade de psicoterapia, isto dificulta o fazer psicológico no NASF.

Hinata: Nós que somos profissionais é que sabemos a diferença (da atuação). No imaginário das pessoas é como se o psicólogo só fosse clínico né! Aquele psicoterapeuta que vai te analisar, que vai trabalhar aquele teu problema e vai querer escutar [...] em várias sessões e que vai ter um trabalho [...] continuado e não é isso, na verdade não é isso, não há uma continuidade, a uma quebra e talvez o sujeito depois precise buscar um acompanhamento, mas que naquele primeiro momento a gente serve para dar auxílio aquela queixa, aquele momento de fragilidade mesmo do sujeito.

Na comunicação sobre a prática psicológica, o diálogo trouxe em suas considerações um outro norte às reflexões sobre ser psicólogo, além das limitações decorrentes de uma infra-estrutura precária para os procedimentos grupais.

Hinata: 0 ambiente, por exemplo, a infra-estrutura, os materiais que deveriam de alguma forma ajudar como: lápis, papel, um ambiente propício para escuta. Outra coisa que a gente se depara e é frustrante é a equipe com quem trabalhamos. Às vezes a relação com essa equipe não é o que a gente espera, espera ter uma relação harmoniosa, em que as divergências sejam trabalhadas e discutidas, mas muitas vezes as pessoas querem agir levando em consideração apenas a sua profissão e a sua função dentro do estabelecimento[...] muitas vezes as pessoas não pensam que talvez a troca de idéias, a troca de saberes vai ajudar naquela intervenção com o sujeito[...] a muito isso[...] discussão um querendo ser melhor que o outro, tem isso né[...] isso dificulta muito o trabalho

Pesquisadora: Então quais seriam as principais dificuldades encontradas para o trabalho do psicólogo no SUS/NASF?

Hinata: 0 principal é realmente a falta de infra-estrutura, o mau funcionamento que na saúde pública é uma coisa defasada, precisaria investimento maior e a gente não tem isso, tem que trabalhar da forma que dá[...] como se tivesse que criar maneiras de trabalhar e não deveria ser assim[...] a gente deveria ter possibilidades para estar criando, inovando[...] e a gente não tem isso[...] tem que procurar um meio uma solução para um problema lá dentro e tentar de alguma forma que nosso trabalho dê certo.

Sem dúvida, o campo de atuação em saúde pública é repleto de aprendizado e desafios. As atividades em equipe contribuem com respostas condizentes às situações clínicas de saúde. É possível trabalhar integrado na equipe multiprofissional? Na opinião de Hinata:"Sim! Acredito que sim, agora é aquela coisa, depende da equipe, não só depende de mim. Na realidade quando a gente fala de "multi" são várias pessoas". Nesse sentido, evidencia a relevância de oportunizar momentos para o grupo partilhar contribuições, seja no matriciamento ou nas Equipes de Saúde da Família.

Hinata: [...] Mas se existe um trabalho realmente em equipe[...] Por exemplo, o que a gente sempre sugere quando está trabalhando em equipe multidisciplinar é que haja reuniões, encontros, debates e eu acho que isso é importante também[...] pessoas que se propõe a participar do trabalho do outro. Ajudar, porque se não houver isso não vai funcionar.

\section{Considerações Finais}

0 estudo assinala a complexidade de ser psicólogo na práxis em saúde pública. A incerteza sobre o fazer, a crescente demanda em saúde mental e os modos de atendimentos orientados pelas políticas de gestão em saúde para a atuação do psicólogo, são algumas das dificuldades trazidas pelo estudo. № desenrolar das comunicações desafios foram realçados - "sair de uma lógica de pensar clínica[...] a clínica "fechada", de consultório ambulatorial, de elite[...] a tradicional clínica psicológica [...] pensar fora das quatro paredes"(Sakura). 
Entendemos que é a partir do fazer-saber em comunidade, que podem se abrir às possibilidades de novas atuações sem uma lógica compromissada com atuações tradicionais em saúde.

Caminhando, pela iluminação das narrativas. Vemos um sentido prejacente da ocupação profissional de psicólogos, de uma atuação reduzida ao atendimento individual em psicoterapia. Moffat (1986) diz ser ela proveniente da importação de modelos de atuação enraizada na cultura pequeno-burguesa européia, na qual, originalmente, esses modelos foram pensados.

A experiência clínica de psicologia no NASF, mostrou barreiras a serem refletidas no que se refere à promoção do cuidado diante de sujeitos em sofrimento em saúde pública. Sugerimos como estratégias de atenção para o cuidado no âmbito do NASF, no Agreste de Pernambuco, encontros sistemáticos entre técnicos e comunitários, tendo em vista que só ocorrem uma vez ao mês, não suficiente para diálogos e trocas necessárias.

Oficinas de formação continuada relacionadas ao trabalho do NASF, podem contribuir com as demandas dos profissionais envolvidos, vez que possibilita problematizar as atuações em campo sanitário, realçando dialogia, vínculos e agentes multiplicadores de transformação social na Atenção Básica em saúde mental. Quando realizadas permitem a escuta dos profissionais, estudo de práticas; encontro com gestores e comunitários na resolução dos problemas de saúde da comunidade.

Seguindo o caminho das constelações comunicadas neste estudo, realçamos possibilidades compreensivas sob a luz dos pressupostos da Fenomenologia Existencial. Barreto (2017, p. 327) comunica que as"atividades de cuidar fazem parte das atividades humanas e das tarefas consideradas próprias dos profissionais de saúde e educação. A prática psicológica se apresenta em diversas modalidades". Cuidado diz:

[...] escutar o clamor da voz da consciência para voltar a si na decisão da autenticidade; como também é des-cuidar-se e retomar modos de ser já definidos e convocados pelos rituais que ocupam o viver os dias e que correspondem ao que nos é familiar e repetimos sem dar por isso. Nesse caminhar no mundo das ocupações, importa chamar atenção para os outros Dasein com os quais con-vivemos. Ocupar-se de outrem deve apresentar-se como um assistir solícito na construção de sentido, abrindo possibilidades para poder-ser (Barreto, 2017, p. 330).

Na ação clínica, enquanto ação preocupada que considera o homem em suas relações com-outros-no-mundo, a atenção psicológica abre possibilidades hermenêuticas sobre a existência. A autora, recorrendo ao pensamento heideggeriano, esclarece que a"ação clínica se revela como ação pré-ocupada, atenta para o modo como o paciente vive, tanto o cuidado de si como a procura de outro modo de estar-uns-com-os-outros, destinando-se e encaminhando sua história" (Barreto, 2017, p. 331).

Desta feita, importa redimensionar a clínica em Núcleos de Apoio a Saúde da Família, tendo um olhar que possa transcender a concepção de matriciamento, quase sempre fundamentada no vitalismo e no assistencialismo vigentes em saúde pública. É preciso revisitar dimensões existenciais como luz à abertura do cuidado que já somos. 0 caminho trilhado neste estudo põe a vista a complexidade do horizonte compreensivo acerca da prática psicológica em território sanitário.

\section{Referências}

Aun, H. A. (2005). Trágico avesso do mundo: Narrativas de uma prática psicológica numa instituição para adolescentes infratores. São Paulo: s.n., 136 p. Dissertação de Mestrado - Instituto de Psicologia da Universidade de São Paulo, São Paulo, SP, Brasil.

Barreto, C. (2017). O Tempo do cuidado na análise existencial de Heidegger e suas ressonâncias na ação clínica. In: Intencionalidade e cuidado. Herança e repercussão da fenomenologia. V Congresso Luso-Brasileiro de Fenomenologia - III Jornadas Ibéricas de Fenomenologia. Organização Bernhard Sylla Irene Borges-Duarte. Edição do Centro de Estudos Humanísticos da Universidade do Minho. Edições Húmus, p. 223-337

Benjamin, W. (1994). O Narrador: considerações sobre a obra de Nikolai Leskov. In W. Benjamin. Magia e Técnica, arte e política: ensaios sobre literatura e história da cultura. (pp. 195 - 221). São Paulo, SP: Brasiliense.

Braga, T. B. M, Mosqueira, S. M. \& Morato, H. T. P. (2012). Cartografia clínica em plantão psicológico: investigação interventiva num projeto de atenção psicológica em distrito policial. Temas psicol. [online]. 20(2), pp. 555-570. ISSN 1413-389X. http://dx.doi.org/10.9788/TP2012.2-20.

Brasil, Ministério da Saúde. (2009). Diretrizes do Nasf - Núcleo de Apoio a Saúde da Família. Secretaria de Atenção à Saúde. Departamento de Atenção Básica. Saúde na escola / - Brasília: Ministério da Saúde, $160 \mathrm{p}$.

Caldas, M. T. \& Macedo, S. (2011). Uma análise crítica sobre técnicas de pesquisa fenomenológica utilizadas em Psicologia Clínica. Rev. NUFEN [online]. 3(1), pp. 3-16. ISSN 2175-2591.

Ferreira Neto, J. (2010). A atuação do psicólogo no SUS: análise de alguns impasses. Psicologia Ciência e Profissão, 30(2), pp. 390-403. Conselho Federal de Psicologia Brasília, Brasil.

Flick, U. (2009). Introdução a pesquisa qualitativa. (3. ed). Porto Alegre, RS: Artmed.

Gadamer, H. G. (1986-1999). Verdade e método I. (3.ed), F. P. Meurer, trad. Petrópolis, RJ: Vozes.

Galindo, W. C. M \& Francisco, A. L. (2013). Psicologia e saúde coletiva: notas para debate. In C. Barreto, H. Morato \& M. Caldas(orgs), Prática psicológica na perspectiva fenomenológica(pp.504-521) Curitiba: Juruá.

Heidegger, M. (1927-2012). Ser e tempo. Campinas: Editora da Unicamp.

Klein, A. P\& D'oliveira, A. F. (2017). O "cabo de força"da assistência: concepção e prática de psicólogos sobre o Apoio Matricial no Núcleo de Apoio à Saúde da Família. Cad. Saúde Pública; 33(1): e00158815

Leite, D. C, Andrade, A. B \& Bosi, M. L. M. (2013). A inserção da Psicologia nos Núcleos de Apoio à Saúde da Família. Physis [online]. 23(4), 1167-1187. http://dx.doi.org/10.1590/S0103-73312013000400008.

Medeiros, R. H. A. (2015). Uma noção de matriciamento que merece ser resgatada para o encontro colaborativo entre equipes de saúde e serviços no SUS. Physis:Revista de Saúde Coletiva, 25(4), 1165-1184. https://dx.doi. org/10.1590/S0103-73312015000400007

Moffat, A. (1986). Psicoterapia do Oprimido: ideologia e técnica da psiquiatria popular. Trad. Paulo Esmanhoto. São Paulo: Cortez.

Pelizzoli, M \& Nunes, J. (2011). 0 fenômeno da saúde - o cuidado a luz da hermenêutica filosófica. In: M. Pelizzoli(org).Saúde em um novo paradigma alternativas ao modelo da doença. Editora Universitária UFPE. Recife.

Perrella, A. C. (2015). A experiência da Psicologia no NASF: capturas, embates e invenções. Pontifícia Universidade Católica de São Paulo, São Paulo, Brasil. Gerais: Revista Interinstitucional de Psicologia, 8 (2), jul - dez, p. $443-452$

Prado, R. A \& Caldas, M. T. (2015). Fenomenologia e Narrativa: Percurso Metodológico de Uma Pesquisa em Psicologia Clínica. Revista Hermenêutica Filosófica, Psicologias Abril Vol. 1. 
Rogers, C. (1985). Tornar-se pessoa. São Paulo: Martins Fontes.

Rotelli, F. (1991). Jornal CRP - 06. Conselho Regional De Psicologia. 6a Região 72 - Ano 11 - Julho/Agosto. Entrevista eTexto: Sueli Zola. Tradutora durante entrevista: Fernanda Nicácio. p. 04 e 05.

Rolnik, S. (1989). Cartografia Sentimental - Transformaç̧ões contemporâneas do desejo. São Paulo: Estação Liberdade.

Santana, A. M. (2017). Contribuições da Fenomenologia Existencial à prática psicológica em saúde. Ana Maria de Santana; Orientadora: Carmem Lúcia Brito Tavares Barreto. Tese de Doutorado, Programa de Pós-Graduação em Psicologia Clínica, Universidade Católica de Pernambuco, Recife, PE. 2017. 